\title{
Correction to: In Vivo and In Vitro Taste Assessment of Artesunate-Mefloquine, Praziquantel, and Benznidazole Drugs for Neglected Tropical Diseases and Pediatric Patients
}

Janine Boniatti, ${ }^{1,6,7}$ Marcelo R. R. Tappin, ${ }^{1}$ Rafaela G. da S Teixeira, ${ }^{2}$ Tamires de A V Gandos, ${ }^{1,2}$ Luis P. S. Rios, $^{2}$ Izabelle A. M. Ferreira, ${ }^{2}$ Karina C. Oliveira, ${ }^{2}$ Sabrina Calil-Elias, ${ }^{2}$ Aila K. M. Santana, ${ }^{3}$ Laís B. da Fonseca, $^{1}$ Flavio M. Shimizu, ${ }^{4}$ Olívia Carr, ${ }^{5}$ Osvaldo N. OliveiraJr, ${ }^{5}$ Fabio M. L. Dantas, ${ }^{6}$

Fabio C. Amendoeira, ${ }^{1}$ and Alessandra L. Viçosa ${ }^{1}$

Correction to: AAPS PharmSciTech (2022) 23:22

https://doi.org/10.1208/s12249-021-02162-Z

This correction is to update Table 1.

The original article has been corrected.

Publisher's Note Springer Nature remains neutral with regard to jurisdictional claims in published maps and institutional affiliations.

The online version of the original article can be found at https:// doi.org/10.1208/s12249-021-02162-z

\footnotetext{
${ }^{1}$ Oswaldo Cruz Foundation, Sizenando Nabuco Street, 100, Rio de Janeiro, RJ, Brazil.

${ }^{2}$ Faculty of Pharmacy, Federal Fluminense University, Niterói, RJ, Brazil.

${ }^{3}$ Pharmaceutical Laboratory in the State of Pernambuco - Lafepe, Recife, PE, Brazil.

${ }^{4}$ Department of Applied Physics, "Gleb Wataghin" Institute of Physics (IFGW), University of Campinas (UNICAMP), Campinas, SP 13083-859, Brazil.

${ }^{5}$ São Carlos Institute of Physics, University of São Paulo, P.O. Box 369, São Carlos, SP 13560-970, Brazil.

${ }^{6}$ Material Department, National Institute of Technology, Rio de Janeiro, RJ, Brazil.

${ }^{7}$ To whom correspondence should be addressed. (e-mail: janine.boniatti@gmail.com)
} 